\title{
Review: Beef-eating quality: a European journey
}

\author{
L. J. Farmer ${ }^{\dagger}$ and D. T. Farrell \\ Agri-Food and Biosciences Institute, Newforge Lane, Belfast, BT9 5PX, UK
}

(Received 5 July 2017; Accepted 26 April 2018; First published online 13 July 2018)

This paper reviews recent research into predicting the eating qualities of beef. A range of instrumental and grading approaches have been discussed, highlighting implications for the European beef industry. Studies incorporating a number of instrumental and spectroscopic techniques illustrate the potential for online systems to non-destructively measure muscle $\mathrm{pH}$, colour, fat and moisture content of beef with $\mathrm{R}^{2}$ (coefficient of determination) values $>0.90$. Direct predictions of eating quality (tenderness, flavour, juiciness) and fatty acid content using these methods are also discussed though success is greatly variable. $\mathrm{R}^{2}$ values for instrumental measures of tenderness have been quoted as high as 0.85 though $\mathrm{R}^{2}$ values for sensory tenderness values can be as low as 0.01. Discriminant analysis models can improve prediction of variables such as $\mathrm{pH}$ and shear force, correctly classifying beef samples into categorical groups with $>90 \%$ accuracy. Prediction of beef flavour continues to challenge researchers and the industry alike, with $\mathrm{R}^{2}$ values rarely quoted above 0.50 , regardless of instrumental or statistical analysis used. Beef grading systems such as EUROP and United States Department of Agriculture systems provide carcase classification and some indication of yield. Other systems attempt to classify the whole carcase according to expected eating quality. These are being supplemented by schemes such as Meat Standards Australia (MSA), based on consumer satisfaction for individual cuts. In Australia, MSA has grown steadily since its inception generating a 10\% premium for the beef industry in 2015-16 of \$187 million. There is evidence that European consumers would respond to an eating quality guarantee provided it is simple and independently controlled. A European beef quality assurance system might encompass environmental and nutritional measures as well as eating quality and would need to be profitable, simple, effective and sufficiently flexible to allow companies to develop their own brands.

Keywords: bovine, palatability, quality assurance, grading, prediction

\section{Implications}

EU consumption of beef has been in decline for 20 years. This may be, at least in part, due to inconsistencies in eating quality, meaning that the customers cannot be sure of the quality they are purchasing. This review documents numerous examples of grading schemes and technologies that have been studied with the objective of managing and predicting beef-eating quality. The majority of investigations of instrumental methods have been carried out under experimental conditions and require further development and validation, but some grading systems have been proven to work. The research reported herein gives the European beef industry an overview of the development of methods to improve consumers' experience of beef-eating quality.

\section{Introduction}

Beef production in Europe contributes to food security, sustainable land use, the socioeconomic well-being of rural

\footnotetext{
${ }^{\dagger}$ E-mail: linda.farmer@afbini.gov.uk
}

communities, and the gastronomic pleasure of urban and rural consumers across the continent. Beef is also a highvalue product that represents an expensive item in household shopping baskets.

Beef consumption in the EU is $10.9 \mathrm{~kg} /$ person per year, averaged over 28 countries in 2016 (Organisation for Economic Co-Operation and Development, 2017), with considerable variation between the member countries. This is lower than in South American countries (e.g. Argentina, $46.8 \mathrm{~kg}$ ), North America (e.g. United States, $25.0 \mathrm{~kg}$ ) and Australia $(21.9 \mathrm{~kg})$, but considerably higher than China $(4.0 \mathrm{~kg})$. However, consumption in developed countries has declined over the last 20 years, by $12 \%$ in the EU, $19 \%$ in the United States and 20\% in Australia. Together with adverse publicity concerning environmental, health, authenticity and safety issues, inconsistent quality may have contributed to this decline.

The beef industry in Europe is exceedingly diverse. The breeds of cattle and the regimes for rearing them have been adapted over centuries to suit the climate and the availability of grazing and feed throughout the seasons. The proportion of beef derived from the dairy herd or bulls $v$. steers varies 
between countries (Eurostat, 2016). In 2008, the European Union produced 7.8 million tonnes of beef, $60 \%$ of which came from dairy herds, numbering 22.8 million dairy cows (Sarzeaud et al., 2008). More recent figures from England indicate that half of all beef produced in England is a product of the dairy herd (Vickers et al., 2017). The diversity of breeds, production systems and processing practices can make it difficult to ensure a consistent eating quality in the end product.

Consumers want beef that is safe, nutritious and of goodeating quality (Verbeke et al., 2010b) and it is important that palatability matches expectations. Research conducted on consumers' willingness to pay for additional quality, conducted in several countries (Polkinghorne and Thompson, 2010), have indicated that consumers will pay a higher price for better-eating quality if this can be assured.

This paper reviews the development of beef quality assurance in Europe, in the context of global approaches to assure the eating quality of beef.

\section{Quality assurance of European beef}

The quality of beef first became a concern when beef ceased to be a local product and carcases began to be transported long distances from where they were reared and slaughtered to where they were butchered and consumed (Polkinghorne and Thompson, 2010). This led to the development of 'beef classification systems', designed to describe the commercially important attributes of the carcases and facilitate communication with distant primary producers. The main parameters were carcase weight, age/maturity, sex, fat cover and colour, conformation and freedom from bruising and blemishes. Such systems often came to include marbling, lean colour/appearance, fatness, estimates of yield such as conformation or eye muscle area and reporting of prices. Many of these parameters remain important in modern systems (Bonny et al., 2017).

'Carcase grading', in contrast, has been defined as 'the placing of different values on carcases for pricing purposes, depending on the market and requirements of traders' (AHDB Industry Consulting, 2008). Systems were developed in United Kingdom, Germany, Ireland and France in the 1960s and 1970s, and these evolved under the European Commission into EUROP grading, introduced in 1981. These grading systems are based upon the carcase and have become less useful as beef is traded increasingly as vacuumpacked cuts or boxed product rather than whole carcases. The meat industry's increasing desire to accurately predict the saleable meat yield (\%) of a carcase further highlights the inadequacies of the EUROP system to meet current industry interests. As the prediction of saleable meat yield does not correlate with beef-eating quality, it is not further discussed in this review. However, recent literature regarding the improving saleable meat yield prediction has been extensively reviewed by Craigie et al. (2012). It has also become clear that the tacit assumption that there is a simple relationship between the eating qualities of the cuts within a carcase is not true, but depends on complex interactions with other factors such as hanging, breed, chill rate and ageing (Rhee et al., 2004; Polkinghorne, 2005; Farmer et al., unpublished data).

More recently, local 'farm assurance schemes' have been introduced, which involve product certification, to reassure the customer on issues such as animal welfare, production methods, traceability and good hygienic practice. Examples include Red Tractor Mark (UK), Farm Quality Assurance Scheme (NI) and similar national and regional schemes across Europe (Aragrande et al., 2005; Anonymous. European Commission, Agriculture and Rural Development, 2017). Despite these various schemes, there is evidence that the eating quality of beef in Europe is not consistent. Data from four countries across Europe show that 19\% grilled sirloin, $25 \%$ grilled rump and $53 \%$ roast topside were deemed 'unsatisfactory' by consumers (Farmer et al., 2016). This indicates that beef is not always meeting consumer expectations.

\section{Recent research on the management of beef eating quality}

Much research on beef eating quality has examined the many production and processing factors which can affect eating quality and the scientific mechanisms for these effects. These studies are outwith the scope of this article.

Instead, this article will focus on those studies that address practical mechanisms by which beef eating quality might be managed and predicted in a commercial setting. It is notoriously difficult to judge eating quality from the appearance of the meat and the beef industry and researchers continue to seek methods to improve the consistency of their product. The development and increasing availability of new instrumental technologies have led to studies on their application to eating quality management.

A number of papers have already reviewed aspects of this work. It has been reported (Verbeke et al., 2010a) that European consumer groups considered muscle profiling to be beneficial, suggesting that there is potential for a beef eating quality guarantee system in Europe. Mullen and Troy (2005) highlighted the biochemical predictors for eating quality at early stages postmortem and reviewed the development of techniques for quality prediction. Barbut (2014) highlighted the impact of increasing automation on demand for sensors and control systems to manage quality during meat processing. Polkinghorne and Thompson (2010) have reviewed the development of grading systems.

Recent studies fall into two main categories: (a) Instrumental methods for predicting eating quality and (b) Grading methods for beef eating quality.

\section{Instrumental methods for predicting eating quality}

There has for some time been a demand from the industry for an instrument that could be placed on the beef production 
line, ideally very soon after slaughter, which is able to predict the eating quality of the final product at the point of consumption, some 7 to 21 days or more later. Given the many changes that occur as muscle matures into meat, this is an ambitious target. Nevertheless, work has been conducted in this area, with mixed success.

There are two approaches. The first is to measure online, and non-invasively, parameters that are known to predict eating quality, such as $\mathrm{pH}$ at various times post-slaughter and fat content or depth or marbling. The second aims to predict directly attributes such as tenderness, juiciness or flavour from detailed spectroscopic analyses. This presumes that the chemical parameters underpinning eating quality are sufficiently abundant to be measured by these techniques. Care is required to ensure that any predictions are not circumstantial, or apply only to a limited data set.

The following sections describe the many recent attempts to determine or predict meat quality using various types of instrumentation. These, together with a full list of references consulted, are listed in Supplementary Tables S1 and S2. These different authors use different methods and terminologies to describe their work. For the purpose of this report, we have defined 'prediction' as a forecast of a future result, for example, recording a spectrum at $24 \mathrm{~h}$ postmortem to predict a quality parameter at 14 days. In contrast, when the spectrum and the quality parameter are both recorded at the same time (or where the sample is frozen at that time), we will refer to this as 'measurement'. In addition, a wide range of statistical methods has been used to evaluate the performance of the predictive models described. Some authors have used calibration and validation data sets while others use only calibration data, so care is needed when comparing $R^{2}$ values. Generally speaking, where authors have quoted coefficients of determination $\left(R^{2}\right)$, calibration $\left(R^{2} C\right)$ and/ or validation $\left(R^{2} V\right)$, good performance models should have high values for each or all of these components. In some cases, authors have described the performance of their models using the term 'cross-validation' $\left(R^{2} \mathrm{CV}\right)$. Cross-validation is a process that assesses the prediction on a new set of samples. The 'new set of samples' can either be a sample set of the original data, that has not been used to develop the model (segmented cross-validation) or it can be a completely new set of data independent of that used to create the model (full crossvalidation). Segmented cross-validation is commonly used when full cross-validation would be too time consuming or when all the samples are analysed together (Wu and Sun, 2013).

Robotic pH. Roehe et al. (2014) were first to report the automated measurement of muscle $\mathrm{pH}$ using a robotic system. Manual (commercial, hand held pH meters) and robotic techniques used to measure muscle $\mathrm{pH}$ at $45 \mathrm{~min}$ postmortem $\left(\mathrm{pH}_{45 \mathrm{mins}}\right)$ were assessed against chemical $\mathrm{pH}$ measuring techniques. Correlation coefficients $(R)$ between the automated methods tested and chemical assessment ranged between 0.38 and 0.47 . The relationship between robotic $\mathrm{pH}$ and $\mathrm{pH}$ measured by chemical analysis explained only $22 \%$ of the variation between methods. Results also showed that the proposed system could operate in a commercial environment and could deal with variations in carcase size, classification and presentation. However, this work highlights several challenges facing robotic systems namely; accuracy, robustness and ease of cleaning of currently available $\mathrm{pH}$ probes.

Computer vision techniques. Jackman et al. (2008) have used a computer vision system to assess colour, marbling fat and also to predict the eating quality of beef aged between 2 and 21 days. In this case, sensory panels (14-day-aged) and Warner Bratzler Shear Force (WBSF days, 2, 7, 14 and 21) measurements were used to assess eating quality. Partial least squares regression techniques showed that sensory 'overall acceptability' and WBSF (day 7) were predicted with $R^{2}$ values of 0.88 and 0.85 , respectively. Other sensory attributes, 'hard' (0.48), 'juice' (0.60) and 'flavour' (0.49) were less well predicted. Jackman et al. (2009) also used multi-linear and partial least squares regression techniques to improve predictions for tenderness (0.72), hard $(0.60)$ and flavour (0.78). Overall acceptability, juice and WBSF (day 21) were predicted with $R^{2}$ values of $0.82,0.46$ and 0.83 , respectively. A model was also created that correctly classified high-and low-quality carcases with $90 \%$ accuracy.

Ultrasound. Ultrasound techniques have been used to predict a number of fat-related variables such as fat depth and intramuscular fat (IMF) with varied success. Aass et al. (2009) showed that ultrasound techniques could be used to predict IMF in lean cattle. A prediction model was developed using stepwise regression procedures to predict IMF with an $R^{2}$ value (validation) of 0.80 . Indurain et al. (2009) also illustrated that measurements of fat thickness, computer image measurement of fatness and ultrasound measurements in combination with carcase fatness or conformation score could improve the prediction of IMF in the longissimus muscle. However, Roehe et al. (2014) have been less successful in predicting fat depth from ultrasound measurements. Results show that the automated robotic measurement of fat depth correlates poorly $\left(R^{2}=0.43\right)$ with the reference method for measuring fat depth (steel ruler).

Computerised tomography imaging (computerised tomography scanning). Computerised tomography scanning techniques have yielded encouraging results in recent years for the prediction of fat, muscle and bone content of beef carcases from a scan of the live animal (Navajas et al., 2010; Prieto et al., 2010) but were less successful at predicting fatty acid profiles and sensory attributes of beef (Prieto et al., 2010).

Navajas et al. (2010) showed that CT carcase images (with entire carcase weight and primal weights) can be used to predict fat, muscle and bone content with $R^{2}$ values between 0.89 to 0.99 , depending on the tissue and whether the calibration or validation data set were analysed. Total carcase tissue was predicted with $R^{2}$ values between 0.95 
and 0.96. Prieto et al. (2010) have used CT scanning to predict the composition, fatty acid content and meat quality aspects of beef. Partial least squares regression techniques were used to analyse CT images, instrumental and sensory data from samples of crossbred Aberdeen Angus and Limousin cattle. $R^{2}$ values for calibration and validation sample sets were obtained for subcutaneous fat $(0.94,0.92)$, IMF $(0.81,0.86)$ total fat $(0.89,0.93)$ and muscle content $(0.99,0.97)$. Fatty acid profiles and IMF were moderately predicted with $R^{2}$ predictions for both sire breeds ranging between 0.61 to 0.75 and 0.71 to 0.76 , respectively. Sensory traits were poorly predicted with $R^{2}$ values ranging between 0.01 and 0.26 . The cost and size of this instrument limits its potential for online use, but it has a valuable role in research and for calibration of other methods.

Magnetic resonance imaging. Magnetic resonance imaging (MRI) has been used to determine the IMF content of beef (Lee et al., 2015). Statistical analysis identified a strong correlation $\left(R^{2}=0.98\right)$ between MRI images and chemical measurements for percentage IMF. Again, the cost and size of this instrument will limit its potential for meat plant use.

VIS-NIR spectroscopy. The spectroscopic measurement of meat quality continues to draw interest (see references in this section and Supplementary Tables S1 and S2). Recent research regarding the eating quality of beef has focussed on prediction or measurement of colour, $\mathrm{pH}$, chemical composition, instrumental, and sensory tenderness and other sensory attributes.

As expected, meat colour is measured well by VisibleNear Infrared (VIS-NIR) spectroscopy. In 2003, Liu et al. (2003) demonstrated that VIS-NIR (400 to $1800 \mathrm{~nm}$ ) methods could measure hunter $a^{*}, b^{*}$ and $E^{*}$ values for beef aged between 2 and 21 days with coefficients of determination $\left(R^{2}\right)$ values ranging between 0.78 and 0.90 . Hunter $L$ values were measured to a lesser extent with $R^{2}$ ranging between 0.49 and 0.55 . Similar measurements for beef colour (longissimus et lumborum) have been quoted with $R^{2}$ values ranging between 0.85 and 0.9 (Andres et al., 2008; Prieto et al., 2009). Related to beef colour, VIS-NIR instruments have also been used to classify dark cutting beef under non-oxygenated and bloomed conditions (Prieto et al., 2014). Partial least squares regression methods have created a model that correctly identified $80 \%$ to $95 \%$ of dark cutting beef samples presented depending on the instrument used and the degree of oxygenation.

The non-invasive $\mathrm{pH}$ measurement of beef muscle would be a valuable asset to meat producers and the application of VIS-NIR spectroscopy has been studied (Andres et al., 2008; Reis and Rosenvold, 2014). The pH of beef, longissimus thoracis, at $24 \mathrm{~h}$ postmortem ( $\mathrm{pH}_{24 \text { hours }}$ ) has been successfully measured at day 1 with $R^{2}=0.97$ (Andres et al., 2008). Reis and Rosenvold (2014) were less successful in predicting ultimate $\mathrm{pH}(\mathrm{pHu})$ from beef samples scanned at 20 to $40 \mathrm{~min}$ postmortem. In the case of the later, partial least squares regression techniques could only predict $\mathrm{pHu}$ with $R^{2}$ between 0.20 and 0.36 . However, further statistical analysis of the same data provided a prediction model that could segregate carcases as normal (pHu <5.8) and high (pHu $>5.8$ ) with $90 \%$ of the high pHu carcases correctly classified.

The chemical composition of beef plays an important role in its eating quality (Su et al., 2014). VIS-NIR spectroscopy has been used to predict beef composition with varying degrees of success. Su et al. (2014) have developed a number of partial least squares regression models from NIR spectroscopic data (1000 to $1800 \mathrm{~nm}$ ) obtained from minced beef samples. These models predict fat, protein and moisture content with $R^{2}$ values for calibration and validation data sets in excess of 0.98 . This finding is supported by Prieto et al. (2011) who have used VIS-NIR spectroscopy (350 to $1800 \mathrm{~nm}$ ) to predict the IMF content in m. longissimus thoracis and longissimus lumborum samples from Limousin and Aberdeen Angus cattle. In this case, IMF was predicted with a cross-validation $R^{2}$ value of 0.75 .

VIS-NIR spectroscopy has been extensively used to both measures and predict the fatty acid content of beef. Sierra et al. (2008) applied NIR spectroscopy (850 to $1050 \mathrm{~nm}$ ) to measure individual and groups of fatty acids present in ground beef samples taken from the longissimus thoracis of yearling bulls. These authors report that prominent fatty acids such as C14:0, C16:0, C16:1 cis9, C17:0, C18:1 cis9 and C18:cis11 were measured with cross-validation $R^{2}$ values greater than 0.76 . Saturated, branched and monounsaturated fatty acids were measured with cross-validation $R^{2}$ values of $0.84,0.70$ and 0.85 , respectively. Similar results for the fatty acid content of beef ( $m$. longissimus thoracis and longissimus lumborum) have been documented by Prieto et al. (2011) using VIS-NIR spectroscopic measurements (350 to $1800 \mathrm{~nm}$ ). Saturated, monounsaturated and polyunsaturated fatty acids were measured with cross-validation $R^{2}$ values of $0.68,0.75$ and 0.64 , respectively. Individual fatty acids (C16:0, C16:1, C18:0, trans 11 C18:1, C18:2 n-6, C20:1, and cis9 trans 11 C18:2) were measured with crossvalidation $R^{2}$ values between 0.69 and 0.90 . However, poorer cross-validation $R^{2}$ values ranging between 0.12 and 0.62 were observed for fatty acids, C14:0, C18:3 n-3, C20:4 $n-6, C 20: 5 n-3, C 22: 6 n-3, n-6$ and $n-3$. The same authors have also investigated the potential for VIS-NIR spectroscopy (400 to $2498 \mathrm{~nm}$ ) to measure concentrations of polyunsaturated fatty acids and their bio-hydrogenation products in the subcutaneous fat of beef cows that were fed flaxseed (Prieto et al., 2012). They suggested that the n-3 fatty acids were measured with $R^{2}$ (coefficient of determination) values ranging between 0.81 and 0.86 and that conjugated linolenic, linoleic and trans-monounsaturated fatty acids were measured with respective $R^{2}$ values of 0.85 , 0.90 and 0.84 to 0.90 . Both papers reported difficulties in determining (prediction and measurement) individual polyunsaturated fatty acids. Sierra et al. (2008) suggests that the failure to accurately determine individual fatty acids could be related to similarities in the NIR absorption spectra of all fatty acids. Prieto et al. (2012) proposed that high levels of unsaturation in some fatty acids reduce the number of $\mathrm{C}-\mathrm{H}$ 
bonds and therefore make a determination by NIR more difficult. However, the same reasoning could also explain why some of the other fatty acid groups are determined with high $R^{2}$ values. It is unclear from these reports whether individual fatty acids are actually being quantified or whether chemically related groups of compounds (e.g. saturated, $n-3, n-6$ fatty acids) are measured with strong correlation within these groups.

The accurate online prediction of beef tenderness continues to elude researchers and processors. Recent research indicates that VIS-NIR spectroscopy techniques only moderately predict or measure sensory tenderness, with slightly better results for instrumental tenderness. Venel et al. (2001) have studied the potential for NIR spectra $(750$ to $1100 \mathrm{~nm})$ to 'predict' WBSF of 14-day-aged beef (semimembranosus). Here, $R^{2}$ 'prediction' values ranged between 0.54 and 0.74 depending on sample segregation. However, a 'prediction' as defined in this review is a forecast of a future result. In this particular case, NIR spectra of steak samples were collected on the same day as the WBSF assessment thus indicating measurement rather than prediction. Park et al. (2001) recorded improved $R^{2}$ prediction values between 0.61 and 0.69 depending on predictive model and the spectral range studied. The sensory and instrumental tenderness of aged beef ( 2 to 21 days) has been measured with $R^{2}$ values varying between 0.22 and 0.72 (Liu et al., 2003). The same authors quote a moderately poor $R^{2}$ value of 0.58 for sensory chewiness, but they do discuss prediction models capable of correctly classifying $83 \%$ to $96 \%$ of beef samples into 'tender' and 'tough' categories, on the basis of WBSF. Although the authors claim to predict WBSF at various days of ageing, by the definitions used in this paper, this is again a 'measurement' and not a 'prediction', as NIR spectra were recorded on the aged beef samples and not on samples before ageing. Similar $R^{2}$ values (0.65) for measurement of WBSF have been reported by Andres et al. (2008), although $R^{2}$ values for measurements of sarcomere length (0.16) and cooking loss (0.20), indicators of meat tenderness, were much lower than that for WBSF measurement. Prieto et al. (2009) have studied the shear force prediction of beef, aged 3 to 14 days, using both Volodkevitch and slice shear force methods. However, $R^{2}$ values of shear force prediction for these methods were much lower than previously seen for WBSF. Cooking loss and sensory tenderness were only predicted with $R^{2}$ values of 0.35 and 0.28 , respectively.

VIS-NIR spectroscopy has also been used to determine other sensory attributes, but predictions are poor. Authors explain these low measurements and predictions are due to a lack of variation in sensory scores for specific attributes. The juiciness of cooked beef has been determined with $R^{2}$ values of 0.50 (Liu et al., 2003) and 0.21 (Prieto et al., 2009) while flavour, abnormal flavour and overall liking have been predicted with $R^{2}$ values of $0.59,0.22,0.25$ (Prieto et al., 2009).

Hyperspectral imaging. Hyperspectral imaging is a relatively new spectroscopic technique that provides spectral information on a pixel scale in both the visible and short wave IR regions. A recent review (Xiong et al., 2017) and the references in this section (and Supplementary Tables S1 and S2) highlight the increasing popularity of this technique to determine aspects of beef eating quality such as colour, $\mathrm{pH}$, composition and tenderness.

In general, hyperspectral imaging predicts beef colour very well. Wu et al. (2010) have shown how stepwise regression analysis techniques can be used to identify key wavelengths that predict Hunter $L, a^{*}$ and $b^{*}$ values. Multi-linear regression methods were then used to predict $L_{1} a^{*}, b^{*}$ values with $R^{2}$ cross-validation values of $0.92,0.90$ and 0.88 , respectively. These findings have been subsequently improved by the same research group who observed $R^{2}$ cross-validation values of $0.96,0.96$ and 0.97 for prediction of $L, a^{*}$ and $b^{*}$ values. Elmasry et al. (2012) have also investigated the potential of hyperspectral imaging (900 to $1700 \mathrm{~nm})$ to measure beef colour. However, $R^{2}$ crossvalidation values for $L(0.88)$ and $b^{*}(0.81)$ were lower than values reported by $\mathrm{Wu}$ et al. (2010). Furthermore, the measurement of $a^{*}$ values was not reported. These lower levels of colour prediction may be related to the scanning range (short wave IR region) used by EIMasry et al.

Prediction and measurement of $\mathrm{pH}$ have not been as successful as those for colour with $R^{2}$ cross-validation values of 0.86 and 0.73 (Wu et al., 2010; ElMasry et al., 2012). In both cases, partial least squares regression techniques identified specific wavelengths from which multi-linear regression tools were used to create $\mathrm{pH}$ prediction/measurement models. It is interesting to note that discriminant analysis methods have not yet been applied to hyperspectral data in order to predict high and low pHu categories, as was applied successfully to $\mathrm{pH}$ predictions using NIR data (Reis and Rosenvold, 2014).

Partial least square regression analysis of hyperspectral imaging data (900 to $1700 \mathrm{~nm}$ ) has been used to measure water, fat and protein content of beef with $R^{2}$ values of 0.89 , 0.84 and 0.86 , respectively (EIMasry et al., 2013). Total fat and fatty acid contents of Japanese Wagyu beef have been determined using hyperspectral imaging (1000 to $2300 \mathrm{~nm}$ ) and partial least squares regression techniques with varying degrees of success (Kobayashi et al., 2010). Total fat, saturated fatty acids and total unsaturated fatty acids were predicted with $R^{2}$ values of $0.90,0.87$ and 0.89 . Predictions for individual fatty acids ranged from $R^{2}=0.68$ to 0.89 depending on the fatty acid. However, as previously noted with VIS-NIR studies, this work does not report whether individual fatty acids are predicted due to cross-correlation with the main fatty acid groups, saturated, monounsaturated and polyunsaturated fatty acids.

In recent years several authors have documented the prediction and measurement of beef tenderness from the statistical analysis of hyperspectral data. WBSF values of 7-day-aged beef have been predicted from hyperspectral images acquired at 2 days postmortem with an $R^{2}$ crossvalidation value of 0.86 (Wu et al., 2010). Drip loss, a contributing factor to beef tenderness, has been measured 
Review: Beef-eating quality: a European journey

Table 1 Summary of grading systems currently in use to predict beef-quality/eating quality (Farmer et al., 2010a; Polkinghorne and Thompson, 2010; Bonny et al., 2017)

\begin{tabular}{|c|c|c|c|c|}
\hline Grading scheme & Country & Grading unit & Number of grades* & Basis of grading \\
\hline USDA & USA & Carcase & 8 Quality grades & $\begin{array}{l}\text { Sex; carcase weight; marbling; ossification; meat colour, } \\
\text { texture; eye muscle area; ribfat; kidney and perirenal } \\
\text { fat }\end{array}$ \\
\hline Canada & Canada & Carcase & $\begin{array}{l}5 \text { Quality grades } \\
\text { (+ subgrades) }\end{array}$ & $\begin{array}{l}\text { Sex; conformation; carcase weight; marbling; meat } \\
\text { colour, texture; fat colour, thickness }\end{array}$ \\
\hline EUROP & Europe & Carcase & $\begin{array}{l}5 \text { Classification grades } \\
\text { for conformation and } \\
\text { fat ( }+ \text { subgrades })\end{array}$ & Sex; conformation; carcase weight; fat cover \\
\hline JMGA & Japan & Carcase & 5 Quality grades & $\begin{array}{l}\text { Sex; carcase weight; marbling; meat colour, brightness, } \\
\text { texture; fat colour, lustre, texture, firmness, thickness; } \\
\text { eye muscle area, rib thickness }\end{array}$ \\
\hline Korea & South Korea & Carcase & 5 Quality grades & $\begin{array}{l}\text { Sex; carcase weight; marbling; meat colour; fat colour, } \\
\text { firmness, texture, thickness; lean maturity; eye muscle } \\
\text { area, rib thickness }\end{array}$ \\
\hline South Africa & South Africa & Carcase & $\begin{array}{l}3 \text { Classification grades } \\
\text { (+ subgrades) }\end{array}$ & Sex; carcase weight; dentition; ribfat; damage \\
\hline Quality Mark & New Zealand & Carcase & Pass/fail quality grades & $\begin{array}{l}\text { Country of origin; age; handling; absence of growth } \\
\text { promoters; licensed plant; ultimate } \mathrm{pH}\end{array}$ \\
\hline MLC Blueprints (+ updates) & United Kingdom & Carcase & Pass/fail quality grades & $\begin{array}{l}\text { Age/sex; growth rate; diet; EUROP grade/fat class; } \\
\text { transport and lairage handling; slaughter techniques, } \\
\text { defects; hanging; electrical stimulation, chilling and } \\
\text { pH/T decline; maturation }\end{array}$ \\
\hline $\begin{array}{l}\text { Red Tractor and Quality } \\
\text { Standard Marks }\end{array}$ & United Kingdom & Carcase & Pass/fail quality grades & Age/sex; EUROP grade/fat class; maturation \\
\hline AUS-MEAT & Australia & Carcase & Classification grades & $\begin{array}{l}\text { Diet; carcase weight; dentition; fat; sex; shape; marbling; } \\
\text { meat colour; fat colour }\end{array}$ \\
\hline MSA & Australia & Cut & 3 Quality grades & $\begin{array}{l}\text { Bos indicus \%; hormonal growth promotor implants; } \\
\text { carcase weight; sex; hump height; electrical } \\
\text { stimulation; hang; marbling; ossification; meat colour; } \\
\text { pHu; ageing time; cooking method }\end{array}$ \\
\hline
\end{tabular}

USDA = United States Department of Agriculture; JMGA = Japanese Meat Grading Association; MLC = Meat and Livestock Commission (now Agriculture and Horticulture Development Board); MSA = Meat Standards Australia; $\mathrm{pHu}=$ ultimate $\mathrm{pH}$.

${ }^{*}$ Classification grades are descriptive terms for the carcase to aid trading while quality grades aim to place a value on the carcase on the basis of its perceived quality. Grades may also indicate yield (Polkinghorne and Thompson, 2010) but this aspect is not discussed in this paper.

from hyperspectral images of beef (taken on same day as reference measurement) with $R^{2}$ values ranging between 0.87 and 0.89 (ElMasry et al., 2011). The prediction of beef tenderness improves when discriminant analysis techniques are used to categorise beef samples into groups. Naganathan et al. (2008) have reported a hyperspectral imaging (400 to $1000 \mathrm{~nm}$ ) model capable of discriminating, but not predicting, 14-day-aged rib eye beef steaks into one of three tenderness categories with $96 \%$ accuracy. These results are supported by Wu et al. (2010) who predicts correct classification of $91 \%$ of tender beef samples applying similar techniques to hyperspectral and WBSF data. Cluff et al. (2013) also showed that linear discriminant models could correctly classify $83 \%$ and $75 \%$ of tough and tender (on slice shear force) samples of longissimus dorsi based on hyperspectral data recorded between 922 and $1739 \mathrm{~nm}$ before sample cooking. Recently, Naganathan et al. (2015) have tested a prototype online hyperspectral instrument (450 to $950 \mathrm{~nm}$ ) for tender prediction of beef. Here, beef samples were scanned at 2 days postmortem after which they were aged to 14 days and evaluated for slice shear force. Results show that $93 \%$ of tender (low shear force) beef samples were correctly classified and that models were also cross-validated with $88 \%$ of validation samples correctly classified. Further field testing of this system using Fisher's linear discriminant, support vector machine and decision tree analyses predict slice shear force of 14-day-aged rib eye beef with test certification accuracy of $87 \%$.

This review highlights the volume of research that has been carried out to assess the potential of hyperspectral imaging to predict instrumental measures of beef-eating quality. However, during this review, we did not find any examples where hyperspectral imaging has been used to accurately predict the sensory qualities of beef.

Raman spectroscopy. The potential to predict sensory eating qualities of beef silverside using Raman spectroscopy has been investigated by Beattie et al. (2004). Partial least 
squares techniques indicate that Raman spectroscopy predicts 'acceptability of texture', 'degree of tenderness', 'degree of juiciness' and 'overall acceptability' of silverside beef with $R^{2}$ values of $0.71,0.65,0.62$ and 0.67 . Interestingly, instrumental shear force measurements were poorly correlated with sensory tenderness $\left(R^{2}=0.15\right)$. The same authors have also investigated the potential to predict the fatty acid composition of adipose tissue of numerous species including beef (Beattie et al., 2006). Partial least squares regression techniques predict cis and polyunsaturation $R^{2}$ values of 0.97 . Trans-unsaturation and individual fatty acids were less well predicted with $R^{2}$ values of 0.52 and 0.77 , respectively.

\section{Grading for beef-eating quality}

A number of grading schemes have been applied to eating quality prediction, including those developed by national industry representative bodies in the United Kingdom, Europe, United States, Canada, New Zealand, Japan and South Korea (AHDB Industry Consulting, 2008; Polkinghorne and Thompson, 2010). These are all based upon the grading of carcases. In contrast, the national industry organisation in Australia, Meat and Livestock Australia, has developed a cuts-based grading scheme known as Meat Standards Australia (MSA). Table 1 lists the main grading systems developed by beef organisations across the world. Systems developed by supermarkets and other commercial organisations are generally confidential and are not included.

The United States Department of Agriculture (USDA) grading system dates back to the 1920s and was not originally designed to indicate eating quality (Polkinghorne and Thompson, 2010), but is generally assumed to do so. This relationship appears to be marked only for extremes. Consumers did not differentiate between beef of intermediate quality USDA grades, but sirloins (m. longissimus lumborum) from higher quality grades were better than lower quality grades (Tedford et al., 2014). These authors observed the same trend for beef graded with the Canadian system. O'Quinn et al. (2015) reported that American consumers were unable to detect differences in eating quality among tenderloin steaks from USDA and select grades. Thus large differences in grade give eating quality differences, but smaller differences do not. It has been shown that USDA maturity bands do not influence eating quality in grainfinished cattle up to 30 months and that only marbling is important (Acheson et al., 2014). Mateescu et al. (2016) reported that WBSF, IMF, hot carcase weight and marbling score predicted eating quality of sirloin better than did the USDA grade. Likewise, the Canadian quality grades, A, AA, AAA did not differentiate beef on cooked tenderness, as measured by shear force (Puente et al., 2016).

The application of the Australian MSA system to European beef has been reviewed by Bonny et al. (2017). The model correctly classifies $50 \%$ to $70 \%$ of the samples with $95 \%$ to $97 \%$ of the predicted scores being within one grade of their consumer scores (Thompson, 2002). The MSA system has been widely tested and validated across Europe since 2003 and has been shown to be applicable to European beef and consumers (Farmer et al., 2009a and 2009b; Legrand et al., 2013; Guzek et al., 2015; Bonny et al., 2017). Studies have also been conducted in South Korea, South Africa, Japan and United States as well as Australia (Polkinghorne, 2007; Polkinghorne et al., 2011). Meat Standards Australia has been shown to be effective in all these countries with some differences due to different expectations and cooking methods. Studies in Northern Ireland showed that MSA could be adapted to improve further the prediction (Farmer et al., $2010 \mathrm{~b}$ ). As all the consumer panels were conducted using the MSA protocol, it has been possible to combine the consumer data from Northern Ireland, Ireland, France and Poland to allow further analysis. This work has been reviewed by Bonny et al. (2018).

Few authors have compared quality assurance systems. Smith et al. (2008) concluded that both the USDA and MSA system deliver palatability prediction for consumers in the United States and Australia, respectively. Tedford et al. (2014) reported that the USDA and Canadian grading systems only partially predicted eating quality. Farmer et al. (2010a) reported that MSA and the UK Blueprint system appeared better than USDA and the New Zealand system at assuring eating quality for Northern Ireland's beef, but that, due to the cuts-based system, MSA gave a lower proportion of non-qualifying beef.

Most eating quality systems generally focus primarily on tenderness. However, the flavour is an important factor in acceptability and has been shown to contribute highly to acceptability (Oliver et al., 2006; Polkinghorne, 2007). It is known that consumers can differ in their liking for specific flavours; for instance, American consumers prefer beef from grain-fed animals and rate Australian grass-fed beef lower than Australian consumers (Polkinghorne, 2007). There is also some evidence for flavour differences between muscles (Kukowski et al., 2004; Meisinger et al., 2006). Some muscles from carcases receiving higher USDA grades achieved higher consumer scores for flavour (Legako et al., 2015; Hunt et al., 2016) and that this was associated with changes in volatile flavour compounds (Legako et al., 2015). Recent research has demonstrated clear flavour differences between muscles and packaging treatments which may be explained by the composition of volatile aroma compounds from the cooked beef (Farmer et al., unpublished data). Many of the compounds responsible for flavour are difficult to measure routinely, due to their low concentrations, but marker compounds have been identified that are associated with flavour liking (Farmer et al., 2013). It may be possible to identify specific flavour notes which can enhance liking for some groups of consumers.

\section{Way forward for the European beef industry?}

The European beef industry is conscious of pressures to deliver a safe, environmentally sustainable product with high nutritional value, which also meets the gastronomic 
expectations of the consumer. Individual companies are investing in numerous initiatives to deliver the expected quality and consistency to their retail customers and the final consumer, often working in partnership with beef scientists. Two international workshops between scientists and industry have been convened to discuss these issues and have been reported (Farmer et al., 2016; Farmer et al., 2017). Workshops seeking industry views identified the need for reliable and robust techniques to monitor eating quality and reduce inconsistency as key for the future management of beef quality (Farmer et al., 2016).

The MSA system has been shown to be widely effective in improving eating quality assurance in many countries. Nevertheless, the European beef industry has been slow to implement this system. Some of the reasons are highlighted in a report on the perceptions of the French beef industry (Hocquette et al., 2011), where the system is seen as difficult to implement given the complexity of the beef industry and market. Similar responses have been received anecdotally from the industry in Northern Ireland and Ireland. However, uptake of MSA or related models is continuing, with the development of MSA-type systems in New Zealand and Poland.

It has been proposed that a global version of MSA could be evolved which would combine the advances made in Australia with developments in genetic and other markers for quality (Hocquette et al., 2014). Such a global eating quality model could also incorporate indicators for flavour characteristics, nutritional quality, environmental considerations and economic efficiency for the benefit of not only the consumer but the entire supply chain (Hocquette et al., 2014). Rapid developments in instrumental technologies raise the possibility that this global model could incorporate these instrumental methods when they become sufficiently effective and robust that they can be used on the slaughter or processing line.

Over the next few years, the European beef industry will decide how it plans to meet the challenge of delivering higheating quality to an increasingly perceptive consumer base. It is not yet clear whether the current systems of retailer and company 'specs' will continue or whether new systems will develop which could comprise instrumental monitoring and prediction, a version of MSA, or a new global-eating quality assurance method that incorporates new elements. Whatever system or systems are used they will need to be:

- Profitable - to be commercially viable.

- Simple - at the point of operation.

- Effective - proven to deliver better-eating quality to consumers.

- Flexible - to allow evolution, development and support of existing and new brands.

At the moment, the best chance of predicting eating quality seems likely to be realised by combining the benefits of an eating quality grading system like MSA with the additional measurements provided by an advanced spectroscopic technique such as hyperspectral imaging. What is certain is that the rapid pace of technological development both in terms of monitoring of composition and markers for quality, and the identification of genetic markers, means that there is considerable potential for the European beef supply chain to find new ways to maintain and enhance the quality of its end product.

\section{Acknowledgements}

The authors acknowledge funding for research projects and knowledge exchange workshops from Department of Agriculture, Environment and Rural Affairs (Northern Ireland), InnovateUK, InvestNI, Meat and Livestock Australia, UK Science and Innovation Network and individual meat companies.

\section{Declaration of Interest}

The authors declare that they have no conflict of interest.

\section{Ethics statement}

This paper is a review of the existing published literature and, therefore, no approval by an ethics committee or compliance with national legislation is required.

\section{Software and data repository resources}

This paper is a review of the existing published literature and the data reported is already available from the journals cited.

\section{Supplementary material}

To view supplementary material for this article, please visit https://doi.org/10.1017/S1751731118001672

\section{References}

Aass L, Fristedt CG and Gresham JD 2009. Ultrasound prediction of intramuscular fat content in lean cattle. Livestock Science 125, 177-186.

Acheson RJ, Woerner DR and Tatum JD 2014. Effects of USDA carcass maturity on sensory attributes of beef produced by grain-finished steers and heifers classified as less than 30 months old using dentition. Journal of Animal Science 92, 1792-1799.

AHDB Industry Consulting 2008. Review of the EU Carcase Classification System for Beef and Sheep (EPES 0708/01). A report for DEFRA. AHDB Industry Consulting, Kenilworth, Warwickshire.

Andres S, Silva A, Soares-Pereira AL, Martins C, Bruno-Soares AM and Murray I 2008. The use of visible and near infrared reflectance spectroscopy to predict beef $\mathrm{M}$-longissimus thoracic et lumborum quality attributes. Meat Science 78, 217-224.

Anonymous. European Commission, Agriculture and Rural Development 2017. Food Quality Assurance and Certification Schemes managed within an integrated supply chain. Retrieved on 24 April 2018 from http://ec.europa.eu/agriculture/quality/certification/index2_en.htm

Aragrande M, Segre A, Gentile E, Malorgio G, Giraud Heraud E, Robles Robels R, Halicka E, Loi A and Bruni M 2005. Food supply chains dynamics and quality certification, European Commission. Retrieved on 24 April 2018 from http://ec. europa.eu/agriculture/quality/certification/docs/chain_finrep_en.pdf

Barbut S 2014. Review: automation and meat quality-global challenges. Meat Science 96, 335-345.

Beattie JR, Bell SEJ, Borgaard C, Fearon A and Moss BW 2006. Prediction of adipose tissue composition using Raman spectroscopy: average properties and individual fatty acids. Lipids 41, 287-294. 
Beattie RJ, Bell SJ, Farmer LJ, Moss BW and Desmond PD 2004. Preliminary investigation of the application of Raman spectroscopy to the prediction of the sensory quality of beef silverside. Meat Science 66, 903-913.

Bonny S, Polkinghorne R, Strydom P, Matthews K, Lopez-Fandino R, Nishimura T, Scollan N, Pethick D and Hocquette JF 2017. Quality assurance schemes in major beef-producing countries. New aspects of meat quality (ed. PP Purslow), pp. 223-255. Elsevier Ltd, Oxford, UK.

Bonny SPF, Hocquette J-F, Pethick DW, Legrand I, Wierzbicki J, Allen P, Farmer L Polkinghorne RJ and Gardner GE 2018. The variability of the eating quality of European beef can be reduced by predicting consumer satisfaction. Animal, first published online 2 April 2018, https://doi.org/10.1017/S1751731118000605.

Cluff K, Naganathan GK, Subbiah J, Samal A and Calkins CR 2013. Optical scattering with hyperspectral imaging to classify longissimus dorsi muscle based on beef tenderness using multivariate modeling. Meat Science 95, 42-50.

Craigie CR, Navajas EA, Purchas RW, Maltin CA, Bunger L, Hoskin SO, Ross DW, Morris ST and Roehe R 2012. A review of the development and use of video image analysis (VIA) for beef carcass evaluation as an alternative to the current EUROP system and other subjective systems. Meat Science 92, 307-318.

EIMasry G, Sun DW and Allen P 2011. Non-destructive determination of waterholding capacity in fresh beef by using NIR hyperspectral imaging. Food Research International 44, 2624-2633.

EIMasry G, Sun DW and Allen P 2012. Near-infrared hyperspectral imaging for predicting colour, $\mathrm{pH}$ and tenderness of fresh beef. Journal of Food Engineering 110, 127-140.

EIMasry G, Sun DW and Allen P 2013. Chemical-free assessment and mapping of major constituents in beef using hyperspectral imaging. Journal of Food Engineering $117,235-246$.

Eurostat 2016. Slaughtering in slaughterhouses - annual data. Europa. Retrieved on 7 July 2017 from http://appsso.eurostat.ec.europa.eu/nui/setupDownloads.do

Farmer LJ, Bowe R, Troy DT, Bonny SPF, Birnie J, Dell'Orto V, Polkinghorne RJ, Wierzbicki J, de Roest K, Scollan ND, Henchion M, Morrison SJ, Legrand I, Roehe $\mathrm{R}$, Hocquette JF and Duhem K 2016. Report of the workshop 'Sustainable beef quality for Europe - A workshop for industry and scientists'. Viandes \& Produits Carnés, 32, VPC-2016-2032-2011-2016.

Farmer LJ, Devlin DJ, Gault NFS, Gee A, Gordon AW, Moss BW, Polkinghorne RJ, Thompson JM, Tolland ELC and Tollerton IJ 2009b. Effect of type and extent of cooking on the eating quality of Northern Ireland beef. In Proceedings of the 55th International Congress on Meat Science and Technology, Copenhagen, Denmark, p. PE7.33.

Farmer LJ, Devlin DJ, Gault NFS, Gordon AW, Moss BW, Polkinghorne RJ, Thompson JM, Tolland ELC and Tollerton IJ 2009a. Prediction of eating quality using the Meat Standards Australia system for Northern Ireland beef and consumers. In Proceedings of the 55th International Congress on Meat Science and Technology, 16-21 August 2009, Copenhagen, Denmark, p. PE 7.34.

Farmer LJ, Devlin DJ, Gault NFS, Gordon AW, Moss BW, Polkinghorne RJ, Thompson JM, Tolland ELC, Tollerton IJ and Watson R 2010b. Adaptation of Meat Standards Australia quality system for Northern Irish beef. Advances in Animal Biosciences 1, 127-127.

Farmer LJ, Devlin DJ, Gault NFS, Gordon AW, Moss BW, Tolland ELC and Tollerton IJ 2010a. Comparison of systems for assuring the eating quality of beef. Advances in Animal Biosciences 1, 231-231.

Farmer LJ, Hagan TDJ, Oltra OR, Devlin Y and Gordon AW 2013. Relating beef aroma compounds to flavour precursors and other measures of quality. In Proceedings of the 10th Wartburg Symposium of Current Topics in Flavor Chemistry and Biology (ed. T Hofmann, D Krautwurst and P Shieberle), 16-19 April 2013, Wartburg Flavour Symposium, Eisenach, Germany, pp. 202-210.

Farmer LJ, Straif K, De Smet S, Russo V, Roehe R, Moloney A, Hocquette JF, Farrell D, Polkinghorne R, Wierzbicki J, Searchinger T, Zhang D, Capri E, Ferrari P, Birnie J, Vigano V, McDonnell C, Hadley P, Hagan T and Troy DT 2017. Report of the workshop 'Sustainable beef quality for Europe II - A workshop for industry and scientists'. Viandes \& Produits Carnés, 33, VPC-2017-2033-2012-2018.

Guzek D, Glabska D, Gutkowska K, Wierzbicki J, Wozniak A and Wierzbicka A 2015. Influence of cut and thermal treatment on consumer perception of beef in polish trials. Pakistan Journal of Agricultural Sciences 52, 533-538.

Hocquette JF, Botreau R, Legrand I, Polkinghorne R, Pethick DW, Lherm M, Picard B, Doreau M and Terlouw EMC 2014. Win-win strategies for high beef quality, consumer satisfaction, and farm efficiency, low environmental impacts and improved animal welfare. Animal Production Science 54, 1537-1548.
Hocquette JF, Legrand I, Jurie C, Pethick DW and Micol D 2011. Perception in France of the Australian system for the prediction of beef quality (Meat Standards Australia) with perspectives for the European beef sector. Animal Production Science 51, 30-36.

Hunt MR, Legako JF, Dinh TTN, Garmyn AJ, O'Quinn TG, Corbin $\mathrm{CH}_{\text {, }}$ Rathmann RJ, Brooks JC and Miller MF 2016. Assessment of volatile compounds, neutral and polar lipid fatty acids of four beef muscles from USDA Choice and Select graded carcasses and their relationships with consumer palatability scores and intramuscular fat content. Meat Science 116, 91-101.

Indurain G, Carr TR, Goni MV, Insausti K and Beriain MJ 2009. The relationship of carcass measurements to carcass composition and intramuscular fat in Spanish beef. Meat Science 82, 155-161.

Jackman P, Sun DW, Du CJ and Allen P 2009. Prediction of beef eating qualities from colour, marbling and wavelet surface texture features using homogenous carcass treatment. Pattern Recognition 42, 751-763.

Jackman P, Sun DW, Du CJ, Allen P and Downey G 2008. Prediction of beef eating quality from colour, marbling and wavelet texture features. Meat Science $80,1273-1281$

Kobayashi K, Matsui Y, Maebuchi Y, Toyota T and Nakauchi S 2010. Near infrared spectroscopy and hyperspectral imaging for prediction and visualisation of fat and fatty acid content in intact raw beef cuts. Journal of Near Infrared Spectroscopy 18, 301-315.

Kukowski AC, Maddock RJ and Wulf DM 2004. Evaluating consumer acceptability of various muscles from the beef chuck and rib. Journal of Animal Science $82,521-525$

Lee S, Lohumi S, Lim HS, Gotoh T, Cho BK and Jung S 2015. Determination of intramuscular fat content in beef using magnetic resonance imaging. Journal of the Faculty of Agriculture Kyushu University 60, 157-162.

Legako JF, Brooks JC, O'Quinn TG, Hagan TDJ, Polkinghorne R, Farmer LJ and Miller MF 2015. Consumer palatability scores and volatile beef flavor compounds of five USDA quality grades and four muscles. Meat Science 100, 291-300.

Legrand I, Hocquette JF, Polkinghorne RJ and Pethick DW 2013. Prediction of beef eating quality in France using the Meat Standards Australia system. Animal 7, 524-529.

Liu YL, Lyon BG, Windham WR, Realini CE, Pringle TDD and Duckett S 2003. Prediction of color, texture, and sensory characteristics of beef steaks by visible and near infrared reflectance spectroscopy. A feasibility study. Meat Science 65, 1107-1115.

Mateescu RG, Oltenacu PA, Garmyn AJ, Mafi GG and VanOverbeke DL 2016. Strategies to predict and improve eating quality of cooked beef using carcass and meat composition traits in Angus cattle. Journal of Animal Science 94, 2160-2171.

Meisinger JL, James JM and Calkins CR 2006. Flavor relationships among muscles from the beef chuck and round. Journal of Animal Science 84, 2826-2833.

Mullen AM and Troy DJ 2005. Current and emerging technologies for the prediction of meat quality. In Proceedings of the 55th Annual Meeting of the European-Association-of-Animal-Production, 5-9 September 2004, Bled, Slovenia, pp. 179-190.

Naganathan GK, Cluff K, Samal A, Calkins CR, Jones DD, Lorenzen $C L$ and Subbiah J 2015. A prototype on-line AOTF hyperspectral image acquisition system for tenderness assessment of beef carcasses. Journal of Food Engineering $154,1-9$.

Naganathan GK, Grimes LM, Subbiah J, Calkins CR, Samal A and Meyer GE 2008. Visible/near-infrared hyperspectral imaging for beef tenderness prediction. Computers and Electronics in Agriculture 64, 225-233.

Navajas EA, Glasbey CA, Fisher AV, Ross DW, Hyslop JJ, Richardson RI, Simm G and Roehe R 2010. Assessing beef carcass tissue weights using computed tomography spirals of primal cuts. Meat Science 84, 30-38.

Oliver MA, Nute GR, Furnols MFI, San Julian R, Campo MM, Sanudo C, Caneque V, Guerrero L, Alvarez I, Diaz MT, Branscheid W, Wicke M and Montossi F 2006. Eating quality of beef, from different production systems, assessed by German, Spanish and British consumers. Meat Science 74, 435-442.

O'Quinn TG, Brooks JC and Miller MF 2015. Consumer assessment of beef tenderloin steaks from various USDA quality grades at 3 degrees of doneness. Journal of Food Science 80, S444-\$449. 
Organisation for Economic Co-Operation and Development 2017. Meat consumption (indicator). Retrieved on 23 May 2017 from https://doi.org// 10.1787/fa290fd0-en

Park B, Chen YR, Hruschka WR, Shackelford SD and Koohmaraie M 2001. Principal component regression of near-infrared reflectance spectra for beef tenderness prediction. Transactions of the ASAE 44, 609-615.

Polkinghorne R 2005. Does variation between muscles in sensory traits preclude carcass grading as a useful tool for consumers? In Proceedings of the 50th International Congress of Meat Science and Technology, 8-13 August 2004, Helsinki, Finland, p. 18.

Polkinghorne R 2007. Targeting the consumer demand for beef in Australia, Japan, Korea, Ireland and the United States. In Proceedings of the 60th Reciprocal Meat Conference, Brookings, SD, USA. Retrieved on 24 April 2018 from https://www.meatscience.org/docs/default-source/publications-resources/ rmc/2007/cc1-01.pdf?sfvrsn=77a6bab3_4

Polkinghorne RJ, Nishimura T, Neath KE and Watson R 2011. Japanese consumer categorisation of beef into quality grades, based on Meat Standards Australia methodology. Animal Science Journal 82, 325-333.

Polkinghorne RJ and Thompson JM 2010. Meat standards and grading A world view. Meat Science 86, 227-235.

Prieto N, Dugan MER, Lopez-Campos 0, McAllister TA, Aalhus JL and Uttaro B 2012. Near infrared reflectance spectroscopy predicts the content of polyunsaturated fatty acids and biohydrogenation products in the subcutaneous fat of beef cows fed flaxseed. Meat Science 90, 43-51.

Prieto N, Lopez-Campos O, Zijlstra RT, Uttaro B and Aalhus JL 2014. Discrimination of beef dark cutters using visible and near infrared reflectance spectroscopy. Canadian Journal of Animal Science 94, 445-454.

Prieto N, Navajas EA, Richardson RI, Ross DW, Hyslop JJ, Simm G and Roehe R 2010. Predicting beef cuts composition, fatty acids and meat quality characteristics by spiral computed tomography. Meat Science 86, 770-779.

Prieto N, Ross DW, Navajas EA, Nute GR, Richardson RI, Hyslop JJ, Simm G and Roehe R 2009. On-line application of visible and near infrared reflectance spectroscopy to predict chemical-physical and sensory characteristics of beef quality. Meat Science 83, 96-103.

Prieto N, Ross DW, Navajas EA, Richardson RI, Hyslop JJ, Simm G and Roehe R 2011. Online prediction of fatty acid profiles in crossbred Limousin and Aberdeen Angus beef cattle using near infrared reflectance spectroscopy. Animal 5, 155-165. Puente J, Samanta SS and Bruce HL 2016. Instrumental meat quality characteristics associated with aged $\mathrm{m}$. longissimus thoracis from the four Canadian beef quality grades. Canadian Journal of Animal Science 96, 143-153.

Reis MM and Rosenvold K 2014. Early on-line classification of beef carcasses based on ultimate pH by near infrared spectroscopy. Meat Science 96, 862-869.

Rhee MS, Wheeler TL, Shackelford SD and Koohmaraie M 2004. Variation in palatability and biochemical traits within and among eleven beef muscles. Journal of Animal Science 82, 534-550.

Roehe R, Ross D, Duthie C-A, Lambe N, Anderson C, Broadbent C, Bunger L, England S, Picken A, Robertson R, Peacock A, Green A, Hinz A, Gilchrist J, Richardson Rl, Nath M and Glasbey C 2014. Research towards an Integrated
Measurement of Meat Eating Quality (IMEQ). Final Report 2013. Retrieved on 24 April 2018 from https://www.sruc.ac.uk/download/downloads/id/1875/imeq report.pdf

Sarzeaud P, Dimitriadou A and Zjalic M 2008. EU beef farming systems and CAP regulations. EAAP Technical Series, volume 9, 122 pp. Wageningen Academic Publishers, Wageningen.

Sierra V, Aldai N, Castro P, Osoro K, Coto-Montes A and Olivan M 2008. Prediction of the fatty acid composition of beef by near infrared transmittance spectroscopy. Meat Science 78, 248-255.

Smith GC, Tatum JD and Belk KE 2008. International perspective: characterisation of United States Department of Agriculture and Meat Standards Australia systems for assessing beef quality. Australian Journal of Experimental Agriculture 48, 1465-1480.

Su HW, Sha K, Zhang L, Zhang Q, Xu YL, Zhang R, Li HP and Sun BZ 2014. Development of near infrared reflectance spectroscopy to predict chemical composition with a wide range of variability in beef. Meat Science 98, 110-114.

Tedford JL, Rodas-Gonzalez A, Garmyn AJ, Brooks JC, Johnson BJ, Starkey JD, Clark GO, Derington AJ, Collins JA and Miller MF 2014. U. S. consumer perceptions of U. S. and Canadian beef quality grades. Journal of Animal Science 92, 3685-3692.

Thompson J 2002. Managing meat tenderness. Meat Science 62, 295-308.

Venel C, Mullen AM, Downey G and Troy DJ 2001. Prediction of tenderness and other quality attributes of beef by near infrared reflectance spectroscopy between 750 and $1100 \mathrm{~nm}$; further studies. Journal of Near Infrared Spectroscopy 9, 185-198.

Verbeke W, Perez-Cueto FJA, de Barcellos MD, Krystallis A and Grunert KG 2010a. European citizen and consumer attitudes and preferences regarding beef and pork. Meat Science 84, 284-292.

Verbeke W, Van Wezemael L, de Barcellos MD, Kugler JO, Hocquette J-F, Ueland 0 and Grunert KG 2010b. European beef consumers' interest in a beef eating-quality guarantee insights from a qualitative study in four EU countries. Appetite 54, 289-296.

Vickers M, Brown $C$ and Ford $L$ 2017. Beef production from the dairy herd. Retrieved on 24 April 2018 from http://www.eblex.org.uk/wp/wp-content/ uploads/2013/06/brp_b_beefbbrpmanual_4_beef_production_from_the_dairy_ herd280613.pdf

Wu D and Sun DW 2013. Advanced applications of hyperspectral imaging technology for food quality and safety analysis and assessment: a review - part I: fundamentals. Innovative Food Science \& Emerging Technologies $19,1-14$.

Wu JH, Peng YK, Chen JJ, Wang W, Gao XD and Huang H 2010. Study of spatially resolved hyperspectral scattering images for assessing beef quality characteristics. Spectroscopy and Spectral Analysis 30, 1815-1819.

Xiong ZJ, Sun DW, Pu HB, Gao WH and Dai O 2017. Applications of emerging imaging techniques for meat quality and safety detection and evaluation: a review. Critical Reviews in Food Science and Nutrition 57, $755-768$ 